\title{
Highly Predictable Augmentation of the Alveolar Ridge: Using a Ribbed Titanium Mesh in Two-Stage Implant Surgery at the Mandible. Report of Clinical Cases and Surgical Technique*
}

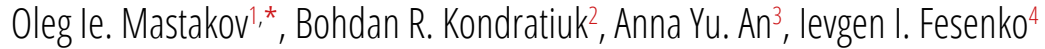 \\ ${ }^{1}$ Scientific Center of Dentistry and Ultrasound Surgery (SCIEDECE). Kyiv Regional Clinical Hospital, Center of Maxillofacial Surgery and \\ Stomatology, Kyiv, Ukraine (Maxillofacial Surgeon) \\ ${ }^{2}$ Director of the Scientific Center of Dentistry and Ultrasound Surgery (SCIEDECE), Kyiv, Ukraine (Oral Surgeon) \\ ${ }^{3}$ Scientific Center of Dentistry and Ultrasound Surgery (SCIEDECE). Department of Oral and Maxillofacial Surgery, Bogomolets National \\ Medical University, Kyiv, Ukraine (Clinical ordinator). \\ Medical University, Kyiv, Ukraine (Clinical ordinator). \\ ${ }^{4}$ Scientific Center of Dentistry and Ultrasound Surgery (SCIEDECE). Department of Oral and Maxillofacial Surgery, PHEI "Kyiv Medical \\ University", Kyiv, Ukraine (PhD, Assis Prof).
}

A B O U T A R T I C L E
Article history:
Paper received 22 July 2017
Accepted 05 September 2017
Available online 30 March 2018
Keywords:
Bone graft
Augmentation of alveolar ridge
Titanium mesh
Implant
Advanced platelet rich fibrin (APRF)
Guided bone regeneration (GBR)

\section{ABOUT ARTICLE}

Augmentation of alveolar ridge

Implant

Guided bone regeneration (GBR)

\begin{abstract}
A B S T R A C T
Purpose.

The aim of this prospective surgical note was to evaluate the highly predictable horizontal bone gain of the alveolar ridge augmentation in two-stage implant surgery at the mandible with titanium mesh.

Material and Methods.

Five patients treated with 10 implants and simultaneous guided bone regeneration with ribbed titanium meshes (i-Gen', MegaGen, Seoul, Republic of Korea) were selected for inclusion in the present surgical note. Primary outcomes were highly predictable horizontal bone gain of the alveolar ridge augmentation, secondary outcomes were biological and prosthetic complications.

Results.

After the removal of titanium meshes, the cone beam computed tomography (СBCT) showed a mean horizontal bone gain of $2 \mathrm{~mm}$. The most frequent complications were mild postoperative edema ( $40 \%$ of patients) and discomfort after surgery ( $60 \%$ of patients); these complications were resolved within one week. Titanium mesh exposure occurred in 0 patients. And implant survival rate of $100 \%$ (implant-based).

Conclusions.

The horizontal ridge reconstruction with titanium meshes placed simultaneously with dental implants achieved
\end{abstract} predictable satisfactory results.

(C) 2018 OMF Publishing, LLC. This is an open access article under the CC BY licence

(http://creativecommons.org/licenses/by-nc/4.0/).

\section{Introduction}

In our opinion the best way to restore partially dentition defect for nowadays is dental implantation.

Dental implants are a predictable treatment procedure for the prosthetic rehabilitation of partially and fully edentulous patients [1-3]. But there is a lot of cases in our everyday practice $(35 \%)$ that seems with CBCT not an adequate bone volume to place implants.

An adequate bone volume is required for insertion of dental implants $[4,5]$; the absence of a sufficient amount

\footnotetext{
* This manuscript has not been presented

* Corresponding author. Sciedece, Scientific Center of Dentistry and Ultrasound Surgery (SCIEDECE),

6 A, Bohatyrska Str., Kyiv 04209, Ukraine.

Tel: +380633269922 Fax.: +380442908030

E-mail address: imastakov@gmail.com (O.I. Mastakov)

Instagram: imastakov; sciedece

UDC: $616.716 .85-089.843: 615.477 .67$

http://dx.doi.org/10.23999/j.dtomp.2018.1.4
}

of horizontal and vertical bone is a problem that can affect the survival and success rates of dental implants in the short, medium, and long term $[4,5]$. Since frequently patients present with bone defects of variable entity [4, 5], different surgical techniques have been proposed to restore the ideal anatomical conditions required for implant insertion or to allow simultaneously positioned implants to succeed [6-14]. These techniques include onlay/inlay bone grafting $[6,7]$, distraction osteogenesis [8], maxillary sinus augmentation [9], inferior alveolar nerve transposition [10], alveolar ridge split [11], and guided bone regeneration (GBR) with resorbable [12] and nonresorbable membranes, such as those in polytetrafluoroethylene (PTFE) [13] or titanium [14], partial extraction therapies [28]. GBR is considered one of the most predictable of these techniques in terms of clinical outcomes, as reported by several systematic reviews of the literature [12-15], particularly where it is employed for the regeneration of defects of small and 
medium entities [16], or around dental implants [17]. The operating principle of GBR involves the placement of a mechanical barrier for the protection of the clot and the isolation of the bone defect from the surrounding connective tissues, in order to facilitate the selective recruitment of the mesenchymal cells responsible for new bone formation $[12-15,17]$ : this can allow the regeneration of the bone defect.

Bone regeneration with GBR has been demonstrated to be predictable, whether or not bioma-terials are positioned below the membrane and are contained by it $[12,14,16]$.

An ideal membrane should possess the following characteristics: biocompatibility, space maintenance capabilities, and ease of use $[13,14,17,18]$. In the last few years, several types of membranes with different designs have been introduced, to facilitate the containment of the rege-nerative material that is often positioned below it and to prevent its dispersion, but also to simplify the work of the surgeon and the application of the membrane itself [13-18].

In particular, the titanium meshes represent a valid solution, because they meet most of the ideal requirements that a membrane should possess $[14,15]$. Several clinical studies have demonstrated that titanium meshes can promote the formation of new bone, when positioned before [19-24] or simultaneously with dental implants [25-27].

The proper placement and stabilization of the titanium mesh into the defect site is of fundamental importance for the success of the regenerative therapy [13, 16-18]; one of the difficulties with these membranes can be related to this, particularly in case of simultaneous placement of the implant, for regeneration of small and medium size defects [17, 18, 25-27].

Recently, titanium meshes that can be fixed directly on the implant have been introduced, but there is still a lack of clinical studies evaluating the efficiency and predictability of these membranes $[18,26]$.

Therefore, the purposes of the report are 1) to evaluate the horizontal bone gain and the de-gree of complications in patients treated with titanium meshes positioned simultaneously with den-tal implants and fixed over them 2) to give for colleagues a new approach for the bone augmenta-tion technique.

In our clinical cases (target group) there were five missed tooth 3.6 (Fig 1) for some years with vestibular horizontal bone atrophy, that we exam on CBCT (Fig 2).
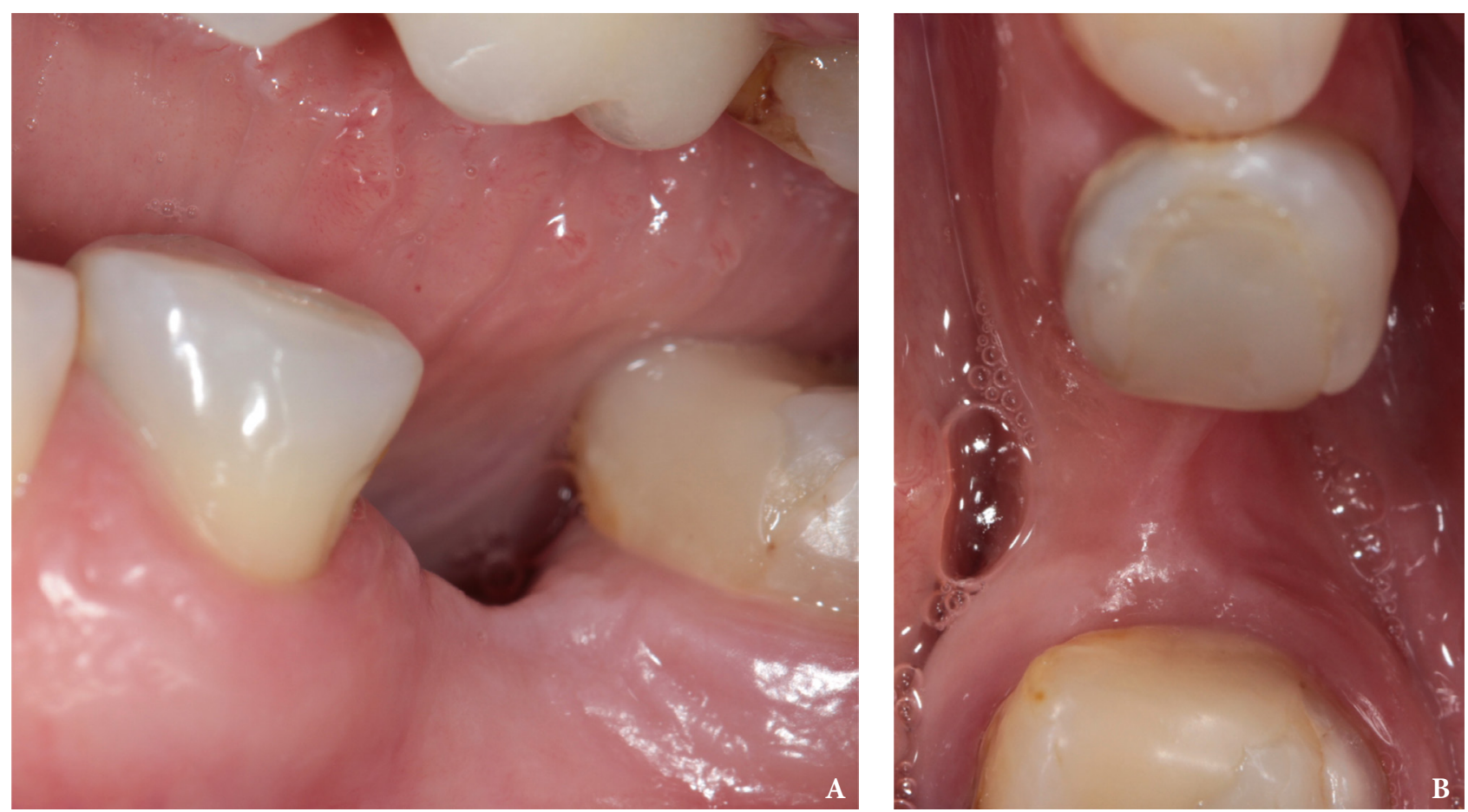

FIGURE 1. Preoperative clinical view in an area of a loosed tooth 3.6. 

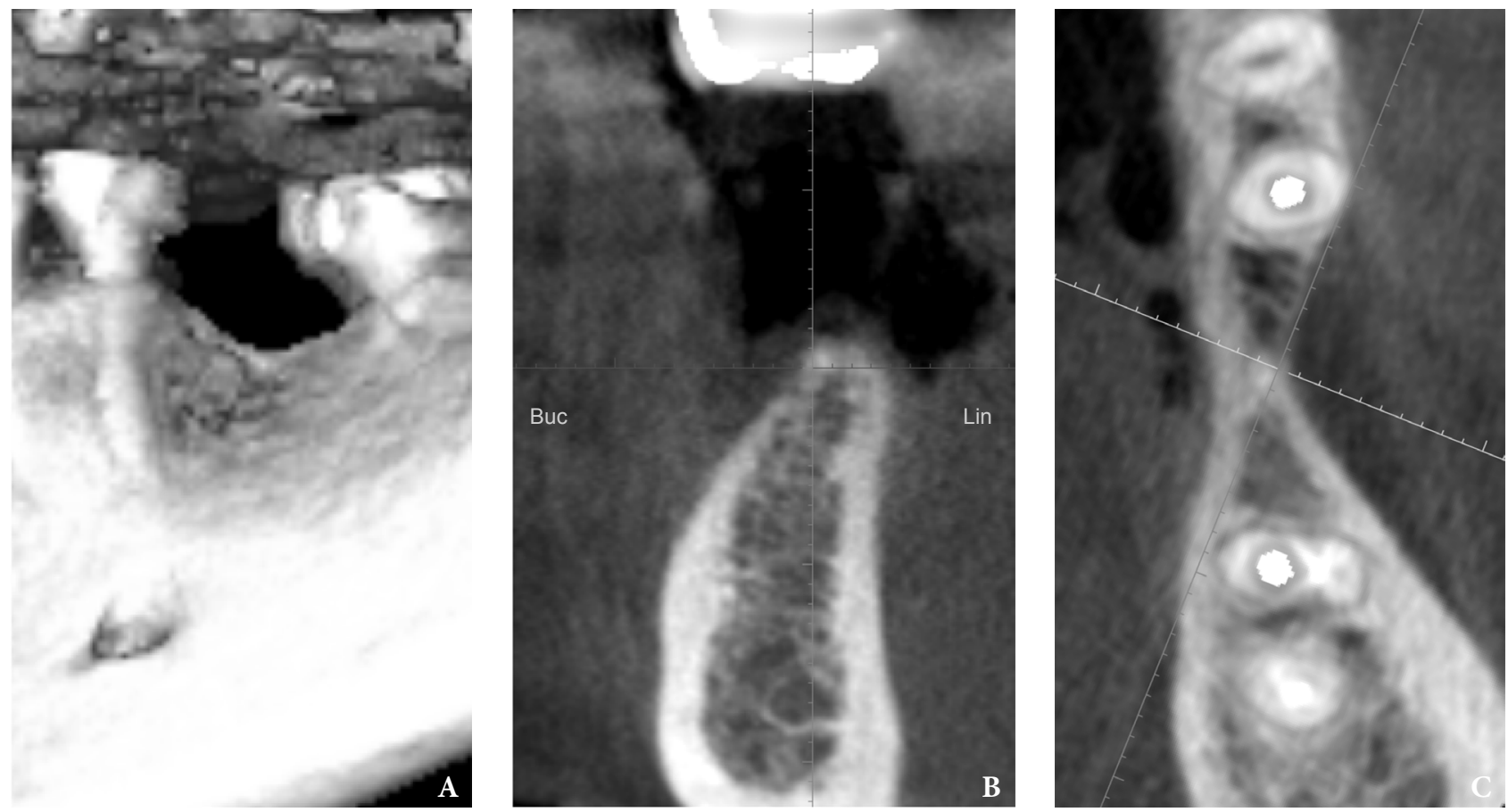

FIGURE 2. Preoperative cone beam computed tomography (CBCT). 3D reconstructed $(\mathbf{A})$, coronal $(\mathbf{B}$ : Buc = buccal side, Lin = lingual side.), and axial $(\mathbf{C})$ scans of the mandibular bone in are of missed tooth 3.6 .

We prefer to restore this partial edentulous using implant placement (AnyOne; MegaGen, Seoul, Republic of Korea) with GBR (Laddec; OST Développement, Clermont-
Ferrand, France) and titanium mesh i-Gen (MegaGen, Seoul, Republic of Korea) (Fig 3) to achieve predictable vestibular bone gain before the implants and do one step surgery.

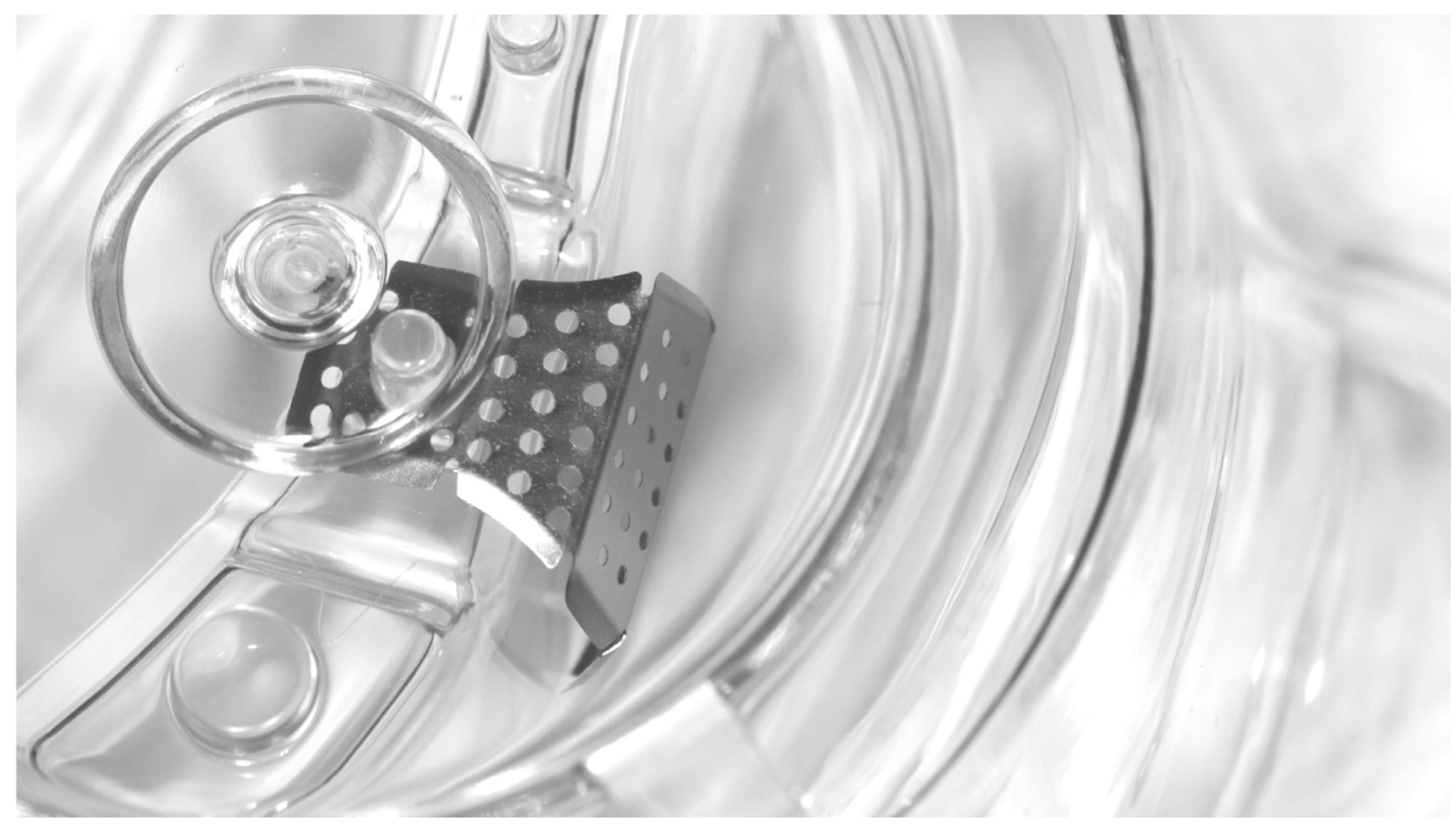

FIGURE 3. Ribbed titanium mesh before bone augmentation surgery at mandible. 

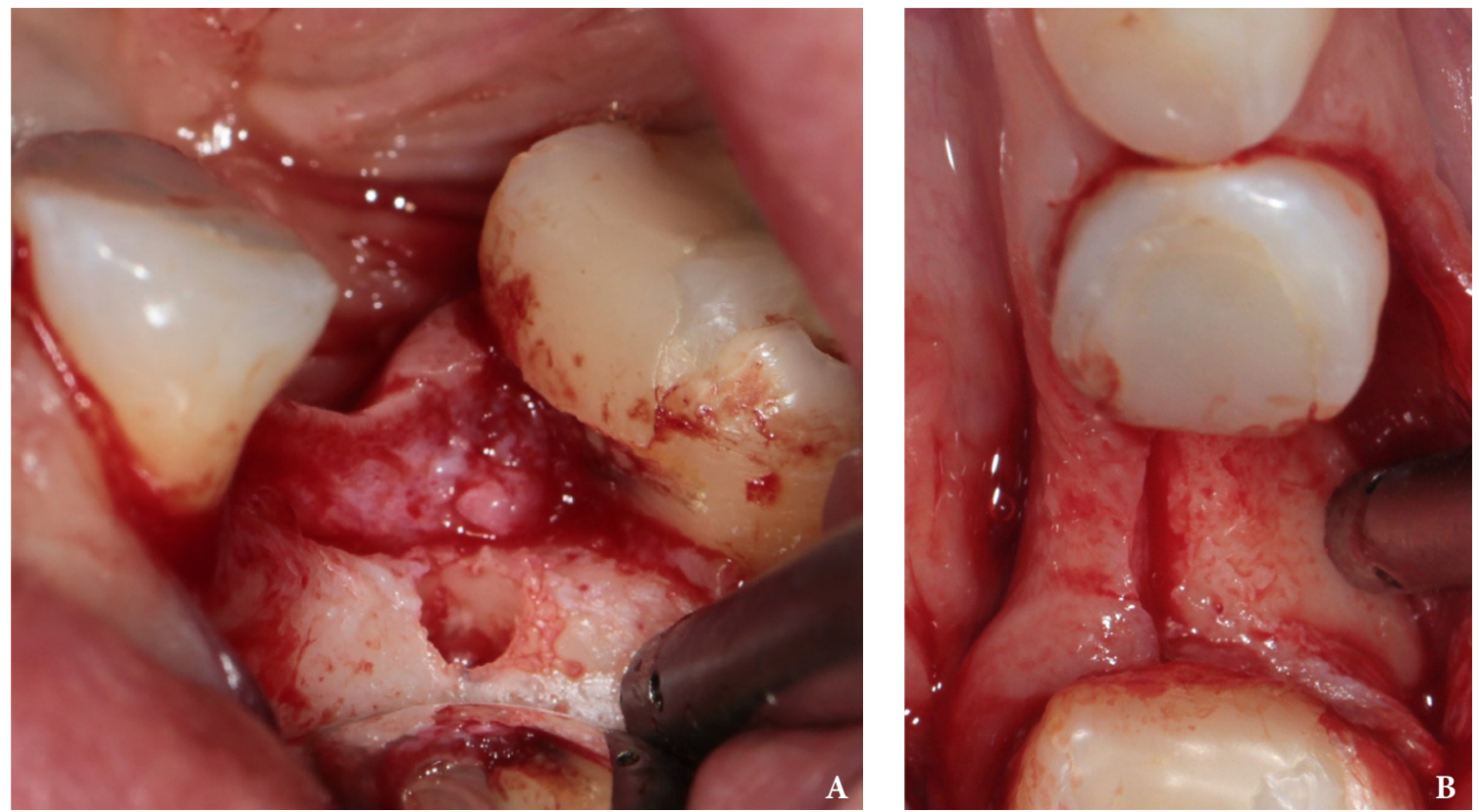

FIGURE 4. Elevation of full-thickness flap exposing the deficient alveolar ridge (A, B). Preparation of the surgical site.

Surgical procedures begins with local anesthesia and incision (one crestal and two horizontal). Full-thickness flap to expose the residual bone (Fig 4). Osteotomy starting with a $2.0 \mathrm{~mm}$ diameter pilot drill, then protocol preparation for implant site we choose (4.0-10, 4.0-11.5, 4.5-10 AnyOne) (Fig 5A). Implant placement. Osteotomy of the cortical bone. Regenerative material (Laddec; OST Développement, Clermont-Ferrand, France) filled the vestibular bone defect and covered with advanced platelet rich fibrin (APRF) [22] and a ribbed titanium mesh (Fig 5B) is fixing on implant with screw (i-Gen; MegaGen, Seoul, Republic of Korea). APRF was achieved using Choukroun A-PRF Centrifuge System (A-PRF' ${ }^{\mathrm{TM}}$; Nice, France). The soft tissues were adapted over the membranes with mobilizing the flap, sutured with horizontal mattress and single loop sutures (Nylon 5.0, RE-SORBA Medical $\mathrm{GmbH}$, Germany) (Fig 5C). Postoperative and 1-week recommendations were given.
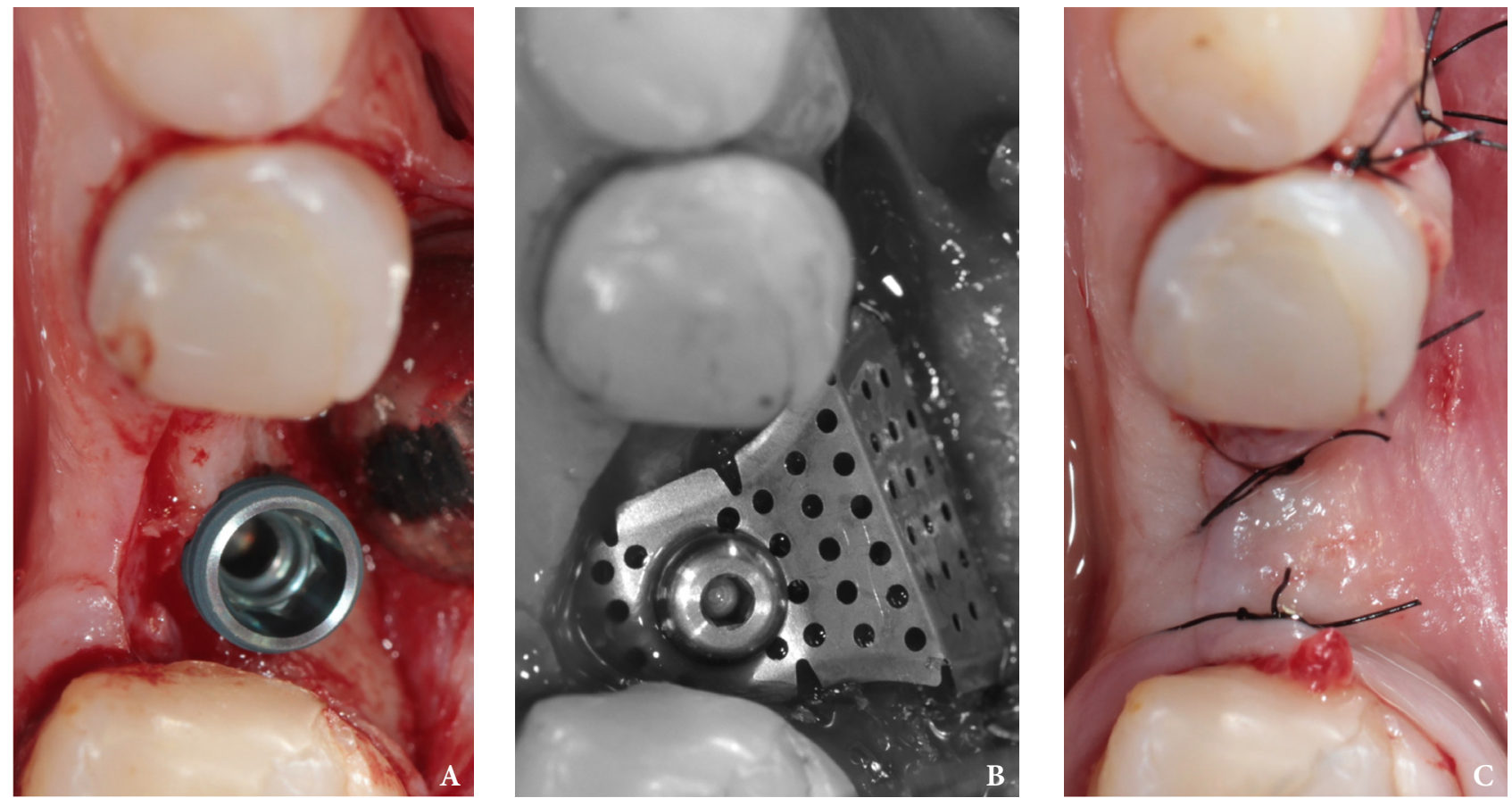

FIGURE 5. Placement the implant (A), titanium mesh $(\mathbf{B})$, and sutures $(\mathbf{C})$. The titanium meshes are connected to the implants and screwed on with the aid of a connecting screw; particulate bone grafts are placed below the titanium mesh screwed on implant. 
After 3 months, a second stage surgery was performed at the recipient sites. The fixtures were uncovered, and the titanium screws and meshes were removed; transmucosal healing abutments were positioned and sutures were performed around them. Two weeks later, impressions were taken, and temporary resin restorations (single crowns, screw-retained) were provided (Fig 6). 1-month later we fixed ceram-zirconia screw retained crowns on titanium-bases (Ti-bases) (Fig 7).
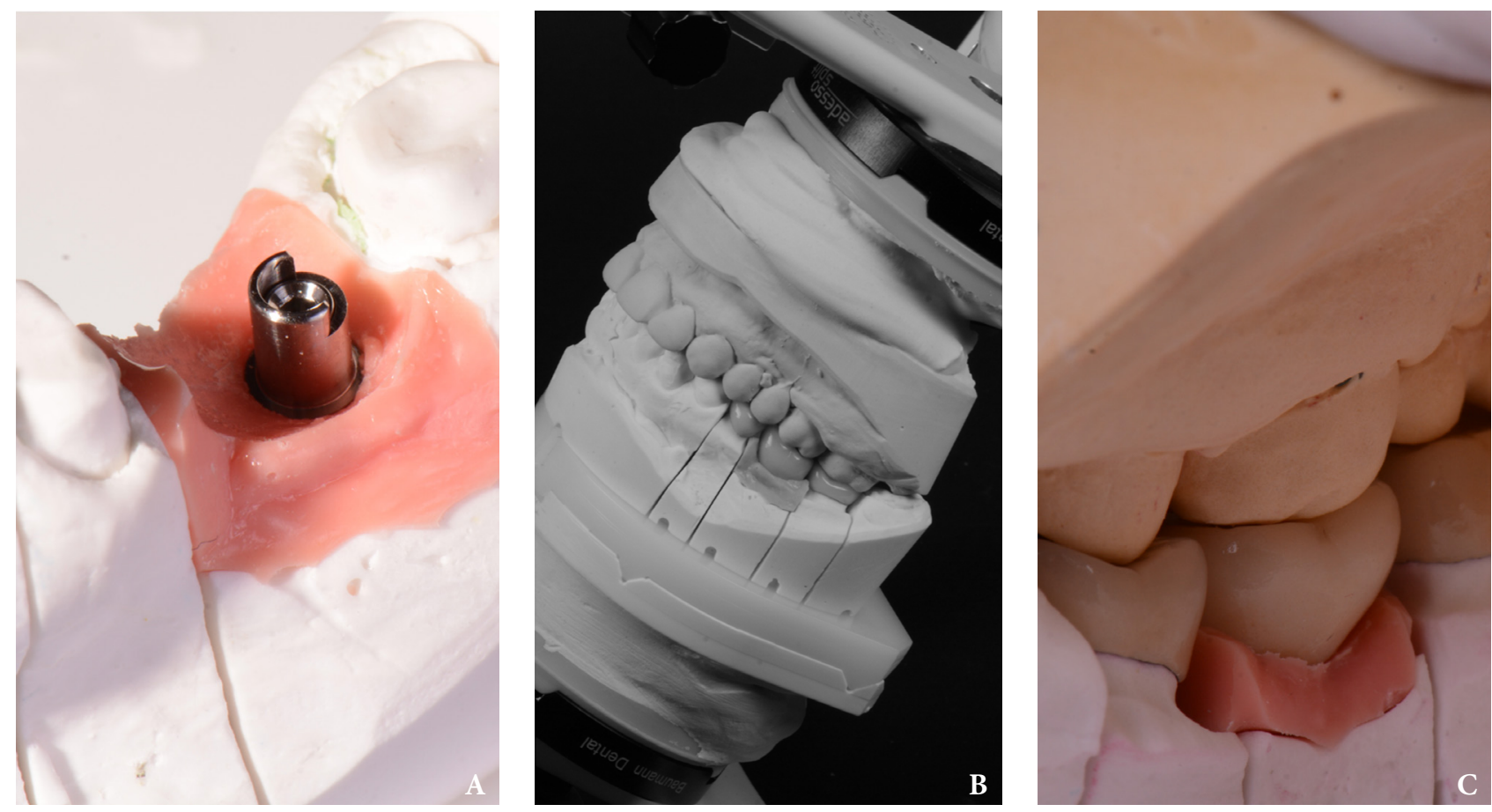

FIGURE 6. Consecutive stages (A-C) of the laboratory workflow.
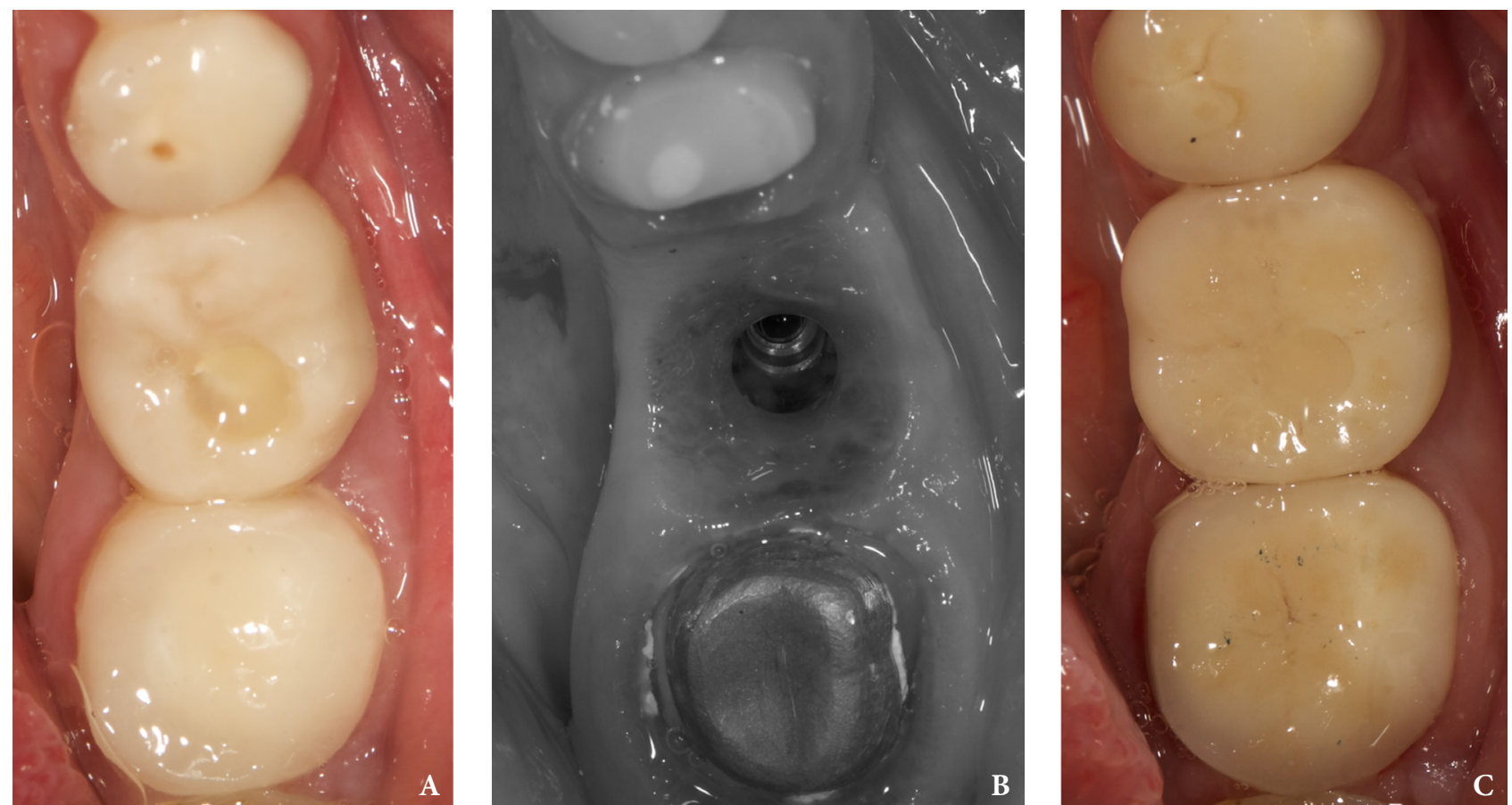

FIGURE 7. View of temporaries (A), emergence profile in keratinized gingiva (B), and fixed cream-zirconia screw retained crown (C). 

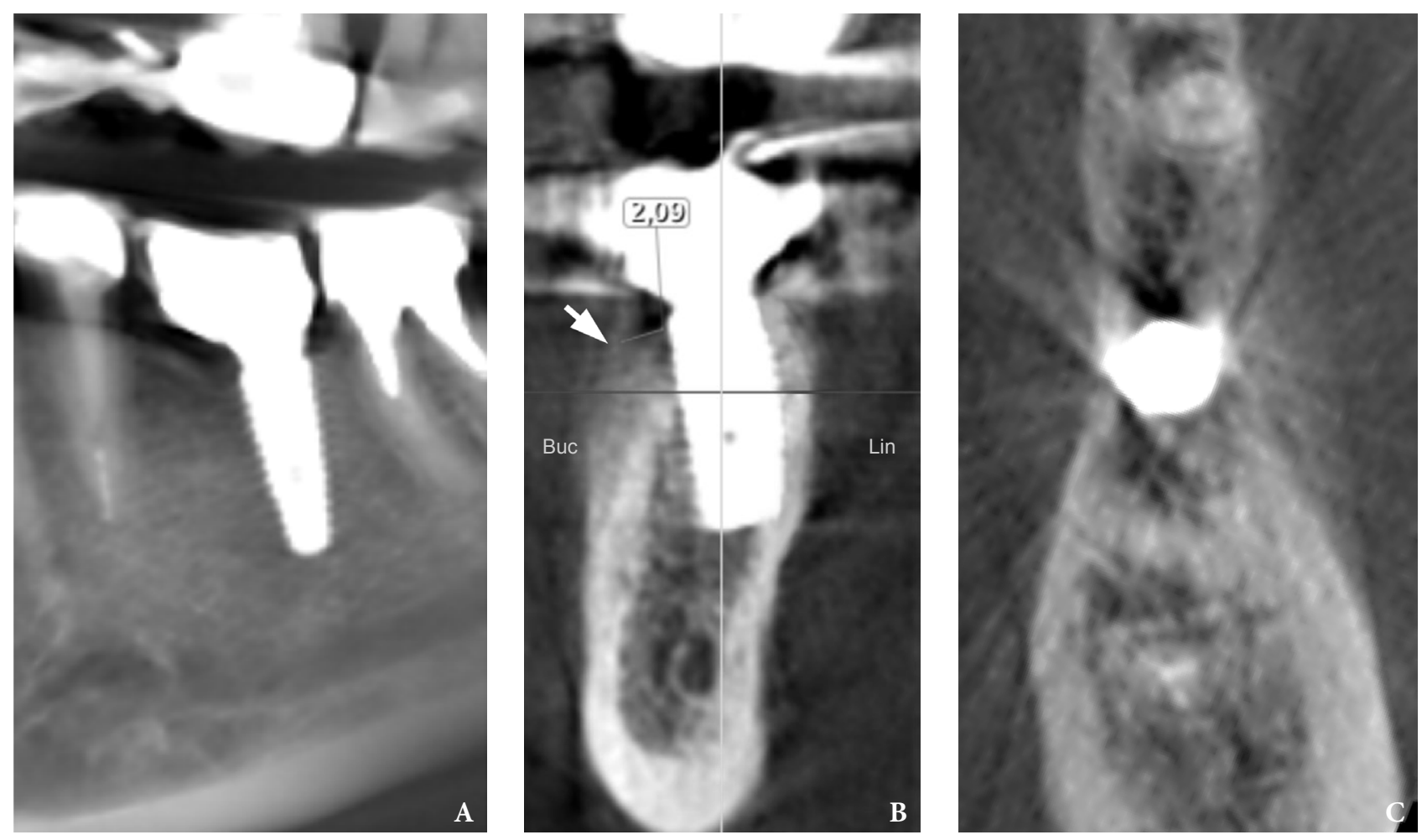

FIGURE 8. CBCT scans (A: panoramic view; B: coronal scan; C: coronal scan) with the highly predictable horizontal modeling of alveolar ridge, 4 months after surgery. (B) Buc = buccal side, Lin = lingual side. Noted additional $2.09 \mathrm{~mm}$ new bone (arrow) at the vestibular side of the implant (at the level of its cervical portion).
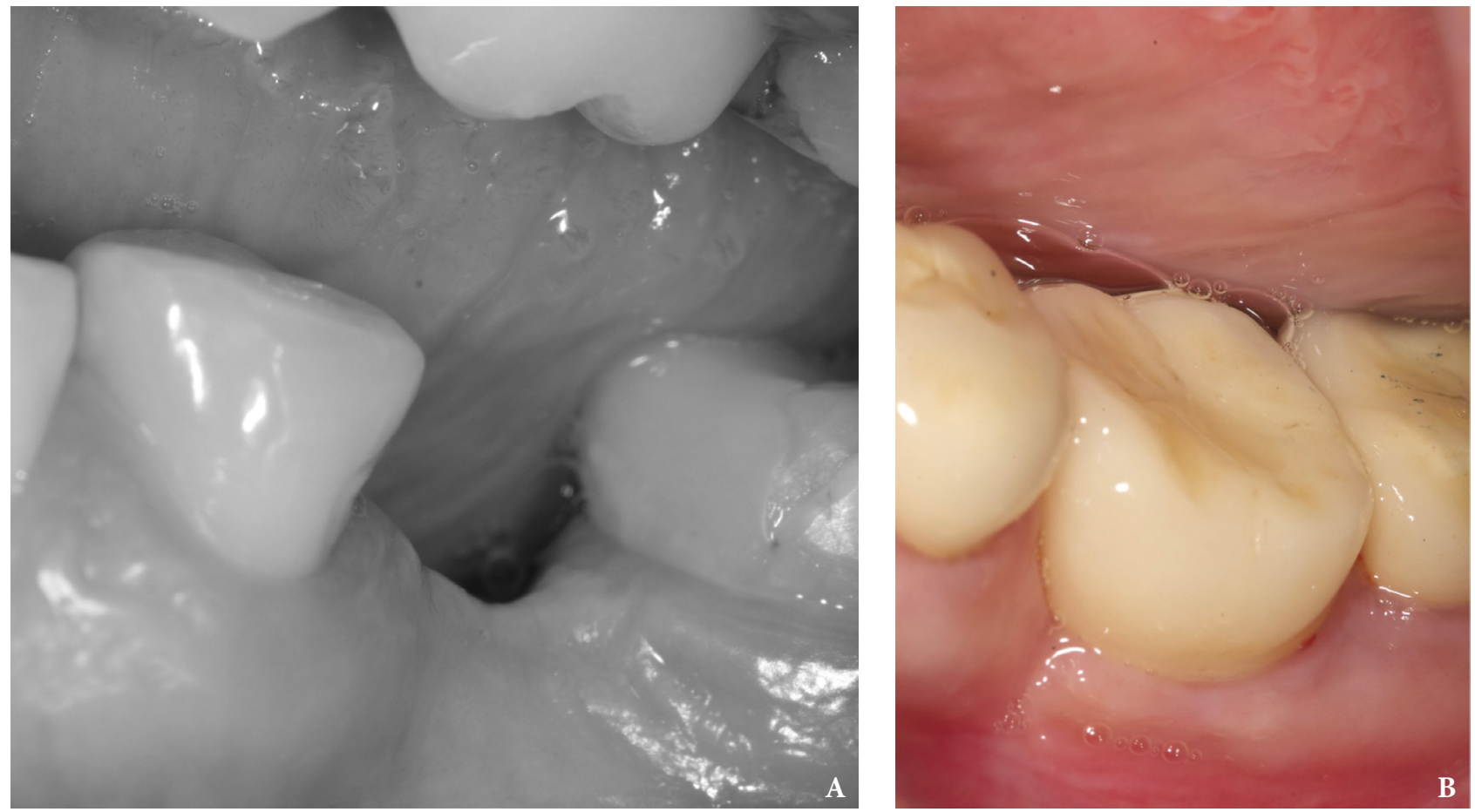

FIGURE 9. The view before (A) and after rehabilitation with permanent crown 4.5-month postoperatively (B). 


\section{PRIMARY OUTCOMES}

Early biological complications: early complications were those that occurred immediately after surgery, or in the immediate aftermath (1-2 weeks), such as pain/discomfort, swelling/edema, and extraoral contusion. No one mesh exposure [22] on regenerative stage we fixed using special design form meshes (i-Gen, MegaGen, Korea).

\section{SECONDARY OUTCOMES}

The highly predictible horizontal augmentation of alveolar ridge were measured in the CBCT sections (in $\mathrm{mm}$ ), 4 months after surgery we done (Fig 8). Pre- and postop clinical photographs (Fig 9) clearly demonstrate very precise result.

\section{Acknowledgements}

The authors thank Yamamoto Center (Kyiv, Ukraine) for the highly precise laboratory procedures.

\section{Conflict of Interests}

The authors declare no conflict of interest.

\section{Role of Author and Co-authors}

Oleg I. Mastakov (material collection, concept of the paper and writing)

Bohdan R. Kondratiuk (material collection)

Anna I. An (material collection)

Ievgen I. Fesenko (editing)

\section{Patient consent}

Written patient consent was obtained to publish the clinical photographs.

\section{Peer reviewed}

Externally peer reviewed.

\section{References}

1. Gehrke SA, Maté Sánchez de Val JE, Ramírez Fernández MP, Shibli JA, Rossetti PH, Calvo-Guirado JL. Stability and crestal bone behavior following simultaneous placement of multiple dental implants (two or more) with the bone splitting technique: a clinical and radiographic evaluation. Clin Implant Dent Relat Res 2016;19(1):123-30.

2. Mangano F, Macchi A, Caprioglio A, Sammons RL, Piattelli A, Mangano C. Survival and complication rates of fixed restorations supported by locking-taper implants: a prospective study with 1 to 10 years of follow-up. J Prosthodont 2014;23(6):434-44.

3. Mangano C, Mangano F, Shibli JA, Ricci M, Sammons RL, Figliuzzi M. Morse taper connection implants supporting 'planned' maxillary and mandibular bar-retained over- dentures: a 5-year prospective multicenter study. Clin Oral Implants Res 2011;22(10):1117-24.

4. Milinkovic I, Cordaro L. Are there specific indications for the different alveolar bone augmentation procedures for implant placement? A systematic review. Int J Oral Maxillofac Surg 2014;43(5):606-25.

5. Rocchietta I, Fontana F, Simion M. Clinical outcomes of vertical bone augmentation to enable dental implant placement: a systematic review. J Clin Periodontol 2008;35(8):203-15.

6. Aloy-Prósper A, Peñarrocha-Oltra D, Peñarrocha-Diago M, Camacho-Alonso F, Peñar-rocha-Diago M. Peri-implant hard and soft tissue stability in implants placed simultaneously versus delayed with intraoral block bone grafts in horizontal defects: a retros-pective case series study. Int $J$ Oral Maxillofac Implants 2016:31(1):133-41.

7. Bechara K, Dottore AM, Kawakami PY, Gehrke SA, Coelho PG, Piattelli A, Iezzi G, Shibli JA. A histological study of non-ceramic hydroxyapatite as a bone graft substitute material in the vertical bone augmentation of the posterior mandible using an interposi-tional inlay technique: a split mouth evaluation. Ann Anat 2015;202:1-7.

8. Menezes DJ, Shibli JA, Gehrke SA, Beder AM, Sendyk WR. Effect of platelet-rich plasma in alveolar distraction osteogenesis: a controlled clinical trial. Br J Oral Maxillofac Surg 2016;54(1):83-7.

9. Mangano C, Sinjari B, Shibli JA, Mangano F, Hamisch S, Piattelli A, Perrotti V, Iezzi G. A human clinical, histological, histomorphometrical, and radiographical study on biphasic ha-beta-tcp 30/70 in maxillary sinus augmentation. Clin Implant Dent Relat Res 2015;17(3):610-8.

10. Pimentel AC, Sanches MA, Ramalho GC, Roman-Torres CV, Manzi MR, Sendyk WR. Lateralization technique and inferior alveolar nerve transposition. Case Rep Dent 2016;2016: 4802637.

11. Elnayef B, Monje A, Lin G, Gargallo-Albiol J, Chan HL, Wang HL, Hernández-Alfaro F. Alveolar ridge split on horizontal bone augmentation: a systematic review. Int $J$ Oral Maxillofac Implants 2015;30(3):596-606.

12. Bottino MC, Thomas V, Schmidt G, Vohra YK, Chu TM, Kowolik MJ, Janowski GM. Recent advances in the development of GTR/GBR membranes for periodontal regenera-tion - a materials perspective. Dent Mater 2012;28(7):703-21.

13. Carbonell JM, Martín IS, Santos A, Pujol A, Sanz-Moliner JD, Nart J. High-density po-lytetrafluoroethylene membranes in guided bone and tissue regeneration procedures: a li-terature review. Int J Oral Maxillofac Surg 2014;43(1)75-84.

14. Rasia dal Polo M, Poli P-P, Rancitelli D, Beretta M, Maiorana C. Alveolar ridge recon-struction with titanium meshes: a systematic review of the literature. Med Oral Patol Oral Cir Bucal 2014;19(6):e639-46.

15. Ricci L, Perrotti V, Ravera L, Scarano A, Piattelli A, Iezzi G. Rehabilitation of deficient alveolar ridges using titanium grids before and simultaneously with implant placement: a systematic review. J Periodontol 2013;84(9):1234-42.

16. Khojasteh A, Soheilifar S, Mohajerani H, Nowzari H. The effectiveness of barrier mem-branes on bone regeneration in localized bony defects: a systematic review. Int J Oral Maxillofac Implants 2013;28(4):1076-89.

17. Merli M, Merli I, Raffaelli E, Pagliaro U, Nastri L, Nieri M. Bone augmentation at im-plant dehiscences and fenestrations. A systematic review of randomised controlled trials. Eur J Oral Implantol 2016;9(1):11-32. 
18. Rakhmatia YD, Ayukawa Y, Furuhashi A, Koyano K. Current barrier membranes: tita-nium mesh and other membranes for guided bone regeneration in dental applications. J Prosthodont Res 2013:57(1):3-14.

19. Malchiodi L, Scarano A, Quaranta M, Piattelli A. Rigid fixation by means of titanium mesh in edentulous ridge expansion for horizontal ridge augmentation in the maxilla. Int J Oral Maxillofac Implants 1988;13(5):701-5.

20. Roccuzzo M, Ramieri G, Bunino M, Berrone S. Autogenous bone graft alone or asso-ciated with titanium mesh for vertical alveolar ridge augmentation: a controlled clinical trial. Clin Oral Implants Res 2007;18(3):286-94.

21. Corinaldesi G, Pieri F, Sapigni L, Marchetti C. Evaluation of survival and success rates of dental implants placed at the time of or after alveolar ridge augmentation with an autogenous mandibular bone graft and titanium mesh: a 3- to 8-year retrospective study. Int J Oral Maxillofac Implants 2009:24(6):1119-28.

22. Torres J, Tamimi F, Alkhraisat $\mathrm{MH}$, et al. Platelet-rich plasma may prevent titanium-mesh exposure in alveolar ridge augmentation with anorganic bovine bone. J Clin Periodontol 2010;37(10):943-51.

23. Her S, Kang T, Fien MJ. Titanium mesh as an alternative to a membrane for ridge aug-mentation. J Oral Maxillofac Surg 2012;70(4):803-10.

24. Poli PP, Beretta M, Cicciù M, Maiorana C. Alveolar ridge augmentation with titanium mesh. A retrospective clinical study. Open Dentistry Journal 2014;8(9):148-58.
25. Von Arx T, Kurt B. Implant placement and simultaneous ridge augmentation using au-togenous bone and a micro titanium mesh: a prospective clinical study with 20 implants. Clin Oral Implants Res 1999;10(1):24-33.

26. Jung GU, Jeon JY, Hwang KG, Park CJ. Preliminary evaluation of a three-dimensional, customized, and preformed titanium mesh in peri-implant alveolar bone regeneration. J Korean Assoc Oral Maxillofac Surg 2014;40(4):181-7.

27. Konstantinidis I, Kumar T, Kher U, Stanitsas PD, Hinrichs JE, Kotsakis GA. Clinical re-sults of implant placement in resorbed ridges using simultaneous guided bone regenera-tion: a multicenter case series. Clin Oral Investig 2015;19(2):553-9.

28. Gluckman H, Salama M, Du Toit J. Partial extraction therapies (PET). Part 1: maintaining alveolar ridge contour at pontic and immediate implant sites. Int J Periodontics Restorative Dent 2016;36:681-7.

29. Lee S-Y, Yang D-J, Yeo S, An H-W, Ryoo KH, Park K-B. The cytocompatibility and osseointegration of the $\mathrm{Ti}$ implants with XPEED ${ }^{\circ}$ surfaces. Clin Oral Implants Res 2012;23(11):1283-9.

30. Gomes RZ, Freixas AP, Han C-H, Bechara S, Tawil I. Alveolar ridge reconstruction with titanium meshes and simultaneous implant placement: a retrospective, multicenter clinical study. Hindawi Publishing Corporation BioMed Research International 2016;Volume 2016: Article ID 5126838, 12 pages. http://dx.doi.org/10.1155/2016/5126838. 